\title{
Heritability of Resistance to Verticillium Wilt in Alfalfa
}

George J. Vandemark, Richard C. Larsen, and Teresa J. Hughes, United States Department of AgricultureAgricultural Research Service, Vegetable and Forage Crops Research Unit, Prosser, WA 99350

\begin{abstract}
Vandemark, G. J., Larsen, R. C., and Hughes, T. J. 2006. Heritability of resistance to Verticillium wilt in alfalfa. Plant Dis. 90:314-318.

Verticillium wilt of alfalfa, caused by Verticillium albo-atrum, may reduce forage yields by up to $50 \%$ in alfalfa-producing areas of the northern United States and Canada. It has been suggested that cultivars require at least $60 \%$ resistant plants to afford maximum protection against disease. Our objective was to calculate heritability estimates of resistance to Verticillium wilt in alfalfa. Estimates were generated for two alfalfa populations developed from the cvs. Affinity $+\mathrm{Z}$ and Depend + EV. Heritability on a half-sib progeny means basis was calculated based on data from greenhouse pathogenicity tests. Estimates based on repeated experiments conducted for single years (2004 and 2005) were high for both populations, ranging from 0.86 to 0.92 . The heritability estimate based on data collected over 2 years was 0.26 for Affinity $+\mathrm{Z}$ and 0.66 for Depend + EV. Disease was more severe in 2005 than in 2004. However, the Spearman rank correlation between mean disease severity index values for half-sib families over 2 years was positive and significant for both populations. Results of pathogenicity tests suggested that neither cultivar had resistance levels approaching $60 \%$. The heritability estimates suggest that resistance levels in both Affinity $+\mathrm{Z}$ and Depend $+\mathrm{EV}$ could be improved further through selection.
\end{abstract}

Verticillium wilt of alfalfa, caused by the soilborne fungus Verticillium alboatrum Reinke \& Berthold, is a serious disease found in North America, primarily in alfalfa-producing areas of the northern United States and Canada $(2,11,13,15,17)$. Initial symptoms of the disease include Vshaped chlorosis of leaf tips, leaf desiccation, and leaf abscission (28). As disease progresses, infected plants wilt and die. Forage yields in alfalfa fields infested with V. albo-atrum may be reduced by $50 \%$ (42). The primary means of dissemination of the pathogen is through infested alfalfa seed (5). Methods for controlling Verticillium wilt of alfalfa include eradication of broadleaf weed hosts, crop rotation for several years with nonhosts, and proper sanitation of equipment (28). However, because several other dispersal mechanism exist, including insects $(19,22-24)$, manure (20), wind (26), and water (6), the abovementioned control strategies have limited efficacy. Although modifying management practices, such as replacing late fall harvests in infected stands with grazing, can reduce disease development (16), the preferable method of control is the use of resistant cultivars $(28,36)$. Several studies have

Corresponding author: G. J. Vandemark E-mail: gvandemark@pars.ars.usda.gov

Accepted for publication 11 October 2005.

\section{DOI: 10.1094/PD-90-0314}

This article is in the public domain and not copyrightable. It may be freely reprinted with customary crediting of the source. The American Phytopathological Society, 2006. indicated that resistance to Verticillium wilt increases both alfalfa yield $(21,34,45)$ and crop profitability (42) when disease is present. Cultivars are considered to be highly resistant (HR) to Verticillium wilt when $\geq 50 \%$ resistant plants are identified when evaluated using a standardized test protocol established by the North American Alfalfa Improvement Conference Committee on Standardized Tests (14).

Resistance to Verticillium wilt is especially important for alfalfa cultivation in the western United States. The disease first was discovered in North America in the Yakima Valley of central Washington (13). In the western United States, the highest yielding stands of alfalfa typically are grown using supplemental irrigation, which has been shown to exacerbate the development of disease (12). In addition, most alfalfa seed in the United States is produced in the western states of Washington, Idaho, and California. The ability of seed producers to export their product to other nations is extremely compromised by the presence of Verticillium wilt in alfalfa seed production fields. For example, because of Verticillium wilt, Australia currently prohibits the importation of all U.S. alfalfa seed, except for that produced in seven counties in California (25).

Various mechanisms have been implicated in the expression of resistance in alfalfa. Rubisco (ribulose-1,5 bisphosphate carboxylase/oxygenase) activity, stomatal conductance, and net photosynthesis were reduced significantly in susceptible plants, whereas resistant plants demonstrated increased Rubisco activity and a decreased regeneration rate of the sugar substrate ribulose-1,5-bisphosphate (RuBP) $(37,38)$. These observations suggest that optimization of carbon assimilation may be a mechanism of resistance. The formation of structures that inhibit proliferation of the pathogen, such as the coating of xylem vessels with suberin, also may contribute to resistance $(31,39)$.

Because alfalfa cultivars typically are synthetic populations resulting from multiple cycles of random mating among selected clones (3), plant breeders have been interested in the combining ability of potential parental clones. Combining ability implies the capacity of a parent to produce superior progenies when combined with another parent (18). General combining ability (GCA) is the average value of a parent (line) estimated on the basis of its performance when crossed with several parents (lines). Specific combining ability (SCA) is the behavior of a parent when crossed with a single parent. GCA effects significantly influenced the expression of resistance to Verticillium wilt in alfalfa $(10,29,35,44)$, indicating that most of the genetic variation for resistance is additive. However, the relative contributions of SCA effects have been found to vary between different resistant cultivars $(29,44)$. Viands (44) observed that the ratio of GCA:SCA effects was 7:1 for a population derived from $\mathrm{cv}$. Vertus, whereas a GCA:SCA ratio of 1.7:1 was observed for another population derived from cv. Maris Kabul. Based on these ratios and an analysis of the distributions of resistance in $S_{1}$ and $F_{1}$ progenies, Viands (44) suggested that resistance to Verticillium wilt was conditioned by different genes in the two cultivars.

Whereas combining ability estimates is used to determine the breeding value of individual parents, heritability estimates can be used to estimate the relative importance of genetic and environmental variance components on trait expression in a given population. Narrow sense heritability $\left(h^{2}\right)$ is defined as the ratio of additive genetic variance $\left(\mathrm{V}_{\mathrm{A}}\right)$ to the total phenotypic variance $\left(V_{P}\right)(8)$. These estimates can be used to determine the correspondence between phenotypic values and breeding values for traits of interest. A narrow-sense heritability estimate of $0.49 \pm 0.16$ has been calculated for resistance to Verticillium wilt in an alfalfa population derived from cvs. Vertus and Saranac (30). The value of the heritability estimate is dependent on both genetic and phenotypic variance components; therefore, any changes in gene frequencies or environ- 
mental conditions will result in different estimates of heritability. Accordingly, the heritability estimate of a trait for a population is considered to be specific for only that population examined under a given set of environmental conditions (8). The objective of this study was to calculate the heritability of resistance in alfalfa to Verticillium wilt using populations derived from two different HR cultivars considered to be adapted for growth throughout the northern United States.

\section{MATERIALS AND METHODS}

Plant materials. Two alfalfa populations were used in this study. In all, 32 half-sib families from Depend + EV and 31 from Affinity $+\mathrm{Z}$ were produced in 1999 in isolation seed cages at Prosser, WA, from randomly selected clones of each of the alfalfa cultivars. Both Depend $+\mathrm{EV}$ and Affinity $+\mathrm{Z}$ have been rated as HR to Verticillium wilt (1).

Inoculations and evaluation of disease severity. For each population, the experimental design involved evaluating eight plants per half-sib family per replicate for resistance to Verticillium wilt, with four replicates for each experiment. This resulted in a total of 32 individual plants being evaluated for each half-sib family in each experiment. Each experiment was conducted twice, once in 2004 and once in 2005. All 32 half-sib families of Depend + $\mathrm{EV}$ and all 31 half-sib families of Affinity $+\mathrm{Z}$ were tested at the same time in both 2004 and 2005.

The standard test protocol for evaluating resistance in alfalfa to Verticillium wilt (14) was used. For each half-sib family, seed was scarified and four rows of approximately $20 \mathrm{seed} /$ row were planted in a single $25-$ by-50-cm flat containing vermiculite. Plants were fertilized weekly with a commercial nutrient solution (Miracle Grow, Marysville, $\mathrm{OH}$ ), and thinned to eight plants/row 4 weeks after sowing. For each experiment, individual flats also were sown at the same time with seed of the three standard checks for resistance to Verticillium wilt, the susceptible (S) cv. Saranac, the resistant (R) cv. Vertus, and the HR cv. Oneida VR (14). Plants were maintained in the greenhouse at 20 to $24^{\circ} \mathrm{C}$ with a 14-h photoperiod, watered as needed to avoid drought stress, and fertilized every other week.

Six weeks after sowing, plants were inoculated with a conidial suspension of $V$. albo-atrum. Three isolates of the pathogen (Nyvall, N29, and W34), all isolated from infected alfalfa plants, were provided by Dr. Mark Smith, Pioneer Hi-Bred International, and used for inoculations. The isolates were maintained on half-strength potato dextrose agar at room temperature. An agar plug of each isolate was placed in a separate flask containing $250 \mathrm{ml}$ of Czapek's Dox broth (43) and the culture was grown at room temperature for 1 week with agitation. Each culture suspension was passed through two layers of cheesecloth. Conidial suspensions were quantified with a hemacytometer and adjusted to a concentration of $1 \times 10^{6}$ conidia/ml. An equal volume of conidial suspension of each isolate was aliquoted to make the inoculum.

Plants were removed from flats and washed free of excess vermiculite. The roots were clipped to approximately $8 \mathrm{~cm}$ in length, and the stems to a length of approximately $3 \mathrm{~cm}$. Plants were immersed completely for $20 \mathrm{~min}$ in the inoculum, which was stirred on a stir plate, and then each plant immediately was transplanted into a $10-\mathrm{cm}$ pot containing commercial potting soil (Sunshine Mix \#1; Sun Gro Horticulture, Bellvue, WA). Pots were randomized in the greenhouse after inoculation.

Plants were evaluated for severity of foliar symptoms 5 weeks after inoculation. Plants were rated for disease severity index (DSI) using an integer scale of 1 to 5 as follows (14): 1 = none or minimal chlorosis of lower leaves; $2=$ chlorosis of lower and middle leaves, but no chlorosis or necrosis of terminal leaves; $3=$ welldeveloped symptoms of chlorotic, necrotic, and twisted terminal leaflets on at least one, but not all main stems; $4=$ severe symptoms of chlorosis, necrosis, and twisting of all leaflets on all main stems; and 5 $=$ dead plant. Plants with a DSI rating $\leq 2$ were classified as being resistant (14).

Estimation of heritability of resistance. Heritability on a half-sib progeny means basis $\left(h^{2}{ }_{P F M}\right)$ was calculated for resistance to Verticillium wilt according to Knapp et al. (27) using the formula $\mathrm{h}_{\mathrm{PFM}}^{2}=$ $1-\mathrm{M}_{2} / \mathrm{M}_{1}$. For estimates based on data from a single year (2004 or 2005), $\mathrm{M}_{2}=$ error mean square and $\mathrm{M}_{1}=$ family mean square. For estimates based on a combined analysis of data from both years, $\mathrm{M}_{2}=$ family-year effects mean square and $\mathrm{M}_{1}=$ family mean square. Exact $90 \%$ confidence intervals were calculated to determine the precision of each heritability estimate on a progeny means basis. The lower $90 \%$ confidence limit (CL) was defined as $1-\left[\left(\mathrm{M}_{1} / \mathrm{M}_{2}\right) \times \mathrm{F}_{1-\alpha / 2 \mathrm{df} 2, \mathrm{df} 1]^{-1} \text { and }}\right.$ the upper $90 \% \mathrm{CL}$ defined as $1-\left[\left(\mathrm{M}_{1} / \mathrm{M}_{2}\right)\right.$ $\left.\times \mathrm{F}_{\alpha / 2: \mathrm{df2}, \mathrm{df}}\right)^{-1}$ (27). The widths of the heritability estimates, which are considered to be indicators of the precision of the heritability estimates, were calculated using the following equation: (upper $90 \%$ $\mathrm{CL}$ - lower $90 \% \mathrm{CL}) / \mathrm{h}^{2}{ }_{\mathrm{PFM}}$ (41). All statistical analyses were conducted using JMP software (version 5.0; SAS Institute, Cary, $\mathrm{NC})$.

\section{RESULTS}

Analysis of disease severity reactions. Significant effects $(P<0.05)$ attributed to differences between half-sib families for DSI were observed for both populations in 2004 and 2005, and also for a combined analysis of data over both years (Table 1). Significant effects attributable to replications were observed for both populations in 2004, but these effects were not significant in 2005. For a combined analysis of data over both years, significant effects also were observed for years, family-year

Table 1. Analysis of variance for disease severity index (DSI) ratings for half-sib families inoculated with Verticillium albo-atrum ${ }^{\mathrm{a}}$

\begin{tabular}{|c|c|c|c|c|c|c|}
\hline \multirow[b]{2}{*}{ Source } & \multicolumn{3}{|c|}{ Affinity + Z } & \multicolumn{3}{|c|}{ Depend + EV } \\
\hline & df & MS & $F($ Prob $>F)$ & $\mathbf{d f} \mathbf{1}^{1}$ & $\mathbf{M S}^{2}$ & $F($ Prob $>F)$ \\
\hline \multicolumn{7}{|l|}{2004} \\
\hline Family & 30 & 1.017 & $6.94(<0.0001)$ & 31 & 1.537 & $8.67(<0.0001)$ \\
\hline Rep & 3 & 0.849 & $5.79(0.0011)$ & 3 & 1.709 & $9.65(<0.0001)$ \\
\hline Error & 90 & 0.147 & $\ldots$ & 93 & 0.177 & $\ldots$ \\
\hline \multicolumn{7}{|l|}{2005} \\
\hline Family & 30 & 2.257 & $9.34(<0.0001)$ & 31 & 2.327 & $12.75(<0.0001)$ \\
\hline Rep & 3 & 0.105 & $0.43(0.7298)$ & 3 & 0.207 & $1.13(0.3406)$ \\
\hline Error & 90 & 0.242 & $\ldots$ & 93 & 0.183 & $\ldots$ \\
\hline \multicolumn{7}{|l|}{2004 and 2005} \\
\hline Family & 30 & 1.017 & $5.24(<0.0001)$ & 31 & 1.537 & $8.54(<0.0001)$ \\
\hline Year & 1 & 28.962 & $149.22(<0.0001)$ & 1 & 103.311 & $574.56(<0.0001)$ \\
\hline Family-year & 30 & 0.757 & $3.90(<0.0001)$ & 31 & 0.524 & $2.91(<0.0001)$ \\
\hline Rep (year) & 6 & 0.477 & $2.46(0.0262)$ & 6 & 0.958 & $5.33(<0.0001)$ \\
\hline Error & 180 & 0.194 & ... & 186 & 0.179 & ... \\
\hline
\end{tabular}

${ }^{a}$ Plants were rated for DSI on a scale of 1 to 5 as follows (14): $1=$ no to minimal chlorosis of lower leaves; $2=$ chlorosis of lower and middle leaves, but no chlorosis or necrosis of terminal leaves; $3=$ well-developed symptoms of chlorotic, necrotic, and twisted terminal leaflets on at least one but not all mainstems; 4 = severe symptoms of chlorosis, necrosis, and twisting of all leaflets on all main stems; and $5=$ dead plant. 
interactions, and replication-within-year interactions (Table 1).

Experiments conducted in 2004 and 2005 included inoculated plants of three populations considered standard checks for evaluating resistance in alfalfa to Verticillium wilt (14). The acceptable range of percent resistant plants allowed for Oneida VR, Vertus, and Saranac when employing the standardized test for evaluating alfalfa for resistance to Verticillium wilt are 55 to 65,30 to 50 , and 0 to $5 \%$, respectively (14). The percentages of resistant plants detected in 2004 exceeded the maximum percentages for all three check populations (Table 2). In 2005, the percentages of plants classified as resistant for Oneida VR, Vertus, and Saranac were all within the acceptable ranges. Results based on inoculations of standard check populations indicate that disease expression was low in 2004, whereas optimal disease expression was observed in 2005.

Least square means analysis indicated that the mean DSI ratings for Affinity $+\mathrm{Z}$ were significantly higher in 2005 than in $2004\left(\mathrm{~F}_{(1,6)}=60.75 ; P=0.0002\right.$; Table 2). Mean DSI ratings for Depend $+\mathrm{EV}$ also were significantly higher in 2005 than in $2004\left(\mathrm{~F}_{(1,6)}=17.98 ; P=0.005\right.$; Table 2). The percentage of resistant plants identified for each population was lower in 2005 than in 2004. Despite a significant year effect on DSI for both Affinity $+Z$ and Depend + EV (Table 1), the Spearman rank correlation between mean DSI values in 2004 and 2005 for the half-sib families of both populations was positive and significant (Table 2), indicating that families with low mean DSI values in 2004 tended to have low means for the experiment conducted in 2005. Similar results also were observed with the check cultivars because, for both years, the mean DSI was lowest for Oneida VR (HR), intermediate for Vertus (R), and highest for Saranac (S).

Heritability of resistance to Verticillium wilt. Heritability estimates based on a single year of data were high $\left(\mathrm{h}_{\mathrm{PFM}}^{2} \geq\right.$ 0.85 ) for both populations (Table 3 ) in both 2004 and 2005. The width of the heritability estimates (Table 3 ), which is the confidence interval width divided by the heritability point estimate, can be considered an indicator of the precision of the estimate (41). The widths based on a single year of data ranged from 8.7 to 18.6 (Table 3 ), indicating that a high degree of precision was associated with the heritability point estimates (41).

Heritability estimates of resistance to Verticillium wilt calculated based on a combined analysis of data across both years were considerably lower for both populations and had larger 90\% CL than estimates based on a single year of data (Table 3). The reduced heritability point estimates coupled with wider CL resulted in heritability estimate widths that were much larger for estimates based on a combined analysis of data across both years.

\section{DISCUSSION}

Miller-Garvin and Viands (30) calculated a heritability estimate of $0.49 \pm 0.16$ for resistance to Verticillium wilt in alfalfa. Similar to the design reported here, MillerGarvin and Viands (30) based their esti- mate on half-sib family means for a population inoculated with a mixture of isolates of $V$. albo-atrum, and rated plants for DSI using the 1-to-5 scale recommended for the standard test for evaluating resistance to Verticillium wilt (14). However, the previously reported estimate was calculated for only a single population based on a single experiment. We have reported heritability estimates for two different populations, with each population being subjected to repeated experiments. The estimates of heritability reported in this study were based on populations derived from two cultivars, both of which had been selected previously for resistance to Verticillium wilt.

Half-sib families and check cultivars exhibited greater disease expression in 2005 than in 2004, suggesting that environmental factors may have been largely responsible for the significant year effect on DSI ratings and also for the significant replication effect observed in 2004 (Table 1). Development of Verticillium wilt in alfalfa involves a host of factors other than the fungus. Drought stress $(14,40)$, nutrient deficiency (14), and temperatures exceeding $24^{\circ} \mathrm{C}(14)$ reduce disease incidence and severity. Conversely, higher levels of irrigation have been shown to enhance symptom development in alfalfa plants grown under both greenhouse (40) and field conditions (12). The temperature range in the greenhouse in this study $\left(20\right.$ to $\left.24^{\circ} \mathrm{C}\right)$ was controlled automatically, but water and fertilizer were applied manually. It is possible that the reduced disease severity in 2004 may have been, in part, the result of

Table 2. Disease severity index (DSI) ratings observed in 2004 and 2005 for half-sib families of alfalfa cultivars Affinity $+\mathrm{Z}$ and Depend + EV inoculated with Verticillium albo-atrum ${ }^{\mathrm{a}}$

\begin{tabular}{|c|c|c|c|c|c|c|c|}
\hline \multirow[b]{2}{*}{ Population $^{\mathrm{b}}$} & \multicolumn{3}{|c|}{2004} & \multicolumn{3}{|c|}{2005} & \multirow[b]{2}{*}{$\rho(\operatorname{Prob}>|\rho|)^{\mathbf{d}}$} \\
\hline & Mean & Range & Resistant plants (\%) & Mean & Range & Resistant plants (\%) & \\
\hline Affinity + Z & 1.91 & $1.15-3.09$ & 70.3 & 3.11 & $1.94-4.75$ & 42.1 & $0.51(0.0031)$ \\
\hline Depend + EV & 2.09 & $1.09-3.68$ & 67.7 & 3.36 & $1.62-4.56$ & 38.3 & $0.70(<0.0001)$ \\
\hline Oneida VR & 1.38 & NA & 90.6 & 2.63 & NA & 56.3 & $\ldots$ \\
\hline Vertus & 1.66 & NA & 84.4 & 3.59 & NA & 34.4 & $\ldots$ \\
\hline Saranac & 3.84 & NA & 21.8 & 4.80 & NA & 1.6 & $\ldots$ \\
\hline
\end{tabular}

a Plants were rated for DSI on a scale of 1 to 5 as follows (14): $1=$ no to minimal chlorosis of lower leaves; $2=$ chlorosis of lower and middle leaves, but no chlorosis or necrosis of terminal leaves; 3 = well-developed symptoms of chlorotic, necrotic, and twisted terminal leaflets on at least one but not all mainstems; 4 = severe symptoms of chlorosis, necrosis, and twisting of all leaflets on all main stems; and $5=$ dead plant. NA = not applicable.

${ }^{b}$ For Affinity + Z, data are presented in each column for an analysis of 31 half-sib families. For Depend + EV, data are presented for an analysis of 32 halfsib families. $\mathrm{N}=32$ plants for each half-sib family. Oneida VR, Vertus, and Saranac = highly resistant (HR), resistant (R), and susceptible (S) check cultivars with 32 plants scored for each check cultivar.

${ }^{c}$ Plants with a DSI rating $\leq 2$ were classified as resistant.

${ }^{\mathrm{d}}$ The Spearman rank correlations ( $\rho$ ) between family means observed in 2004 and 2005.

Table 3. Heritability estimates $\left(\mathrm{h}^{2}{ }_{\mathrm{PFM}}\right)$ on a progeny mean basis with $90 \%$ confidence limits $(\mathrm{CL})$ for resistance to Verticillium albo-atrum in two alfalfa halfsib populations

\begin{tabular}{|c|c|c|c|c|c|c|c|c|c|}
\hline \multirow[b]{2}{*}{ Population $^{\text {a }}$} & \multicolumn{3}{|c|}{2004} & \multicolumn{3}{|c|}{2005} & \multicolumn{3}{|c|}{ 2004-2005 } \\
\hline & $\mathbf{h}^{2}{ }_{\text {PFM }}$ & $90 \% \mathrm{CL}$ & Width $^{b}$ & $\mathbf{h}_{\text {PFM }}^{2}$ & $90 \% \mathrm{CL}$ & Width & $\mathbf{h}^{2}{ }_{\text {PFM }}$ & $90 \% \mathrm{CL}$ & Width \\
\hline Affinity + Z & 0.86 & $0.75-0.91$ & 18.6 & 0.89 & $0.82-0.93$ & 12.3 & 0.26 & $0-0.60$ & 231.8 \\
\hline Depend + EV & 0.89 & $0.81-0.93$ & 13.5 & 0.92 & $0.87-0.95$ & 8.7 & 0.66 & $0.38-0.81$ & 65.2 \\
\hline
\end{tabular}

${ }^{\text {a }}$ For Affinity + Z, data is presented in each column for an analysis of 31 half-sib families. For Depend + EV, data is presented for an analysis of 32 half-sib families. $\mathrm{N}=32$ plants for each half-sib family.

${ }^{\mathrm{b}}$ Expressed as the ratio (\%) of the confidence limit width over the heritability point estimate. 
plants in this experiment suffering an irrigation and nutrient deficit compared with conditions provided for plants in the 2005 experiment due to variation in the manual application of water and nutrients.

The percentages of resistant plants detected in 2004 for both Affinity $+\mathrm{Z}$ and Depend + EV (Table 2) were consistent with both cultivars being rated as HR $(>50 \%)$ for resistance to Verticillium wilt (1). However, these results are likely overestimations of disease resistance ratings, because results for the standard check cultivars indicated that disease pressure was low in 2004. In 2004, both populations had a lower percentage of resistant plants than the check Vertus (R). The percentages of resistant plants detected in 2005 would have resulted in both cultivars being classified as R (31 to $50 \%$; 14 ). Viands et al. (45) similarly observed discrepancies between claimed and observed resistance ratings for alfalfa cultivars inoculated with V. albo-atrum. Viands et al. (45) classified Oneida VR, considered to be HR, as being $\mathrm{R}$ based on results obtained using the standard test protocol (14). In the same report, out of seven cultivars considered to have an $\mathrm{R}$ resistance rating, two were classified as $\mathrm{R}$, whereas the other five were classified as moderately resistant (MR). Among three cultivars considered to be MR, two were classified as having low resistance (LR), and a single cultivar considered to be LR was classified as being S. Both Busch et al. (4) and Viands et al. (45) observed less variation among tests for mean DSI than for percentage of resistance plants, and concluded that mean DSI more reliably expressed levels of cultivar resistance to Verticillium wilt than percentage of resistant plants. Comparisons of mean DSI ratings between the standard check cultivars and Affinity $+\mathrm{Z}$ and Depend + EV suggest that the performance of the two cultivars was more similar to the check Vertus (R) than to the check Oneida VR (HR).

Heritability estimates based on a single year of data were, in all cases, quite high $\left(\mathrm{h}_{\mathrm{PFM}}^{2} \geq 0.85\right.$; Table 3$)$. Heritability estimates based on a single year of data should be considered to reflect maximum estimates of heritability $(32,33)$ because these estimates include nonadditive components of genetic variance among half-sib families, such as family-year and family-yearenvironment interaction variances (32). In this study, family-year effects were significant for both Affinity $+\mathrm{Z}$ and Depend + EV (Table 1). Heritability estimates based on a single year of data were quite similar between Affinity $+Z$ and Depend + $\mathrm{EV}$, with the estimates having a range of 0.86 to 0.92 across both cultivars and both years (Table 3 ). The similar heritability estimates across years and cultivars may reflect similar percentages of alfalfa germ plasm sources that contributed to the gene pools of the two cultivars (3). Flemish alfalfa germ plasm has been proposed to be the initial source of resistance to Verticillium wilt in cultivars developed in the United States (44). Affinity $+\mathrm{Z}$ is estimated to be composed of $36 \%$ Flemish germ plasm, whereas Depend $+\mathrm{EV}$ is estimated to be composed of $33 \%$ Flemish germ plasm (7).

Heritability estimates based on a combined analysis of data collected over 2 years were considerably lower for both populations than estimates based on a single year of data (Table 3). The primary reason for the lower estimates is that, for both populations, significant family-year effects resulted in family-year mean square values that were considerably larger than the error mean square values used for calculating heritability estimates based on a single year of data (Table 1). The heritability point estimate based on data collected over 2 years was considerably lower for Affinity $+\mathrm{Z}$ than for Depend $+\mathrm{EV}$ (Table 3). The family-year mean square was larger for Affinity $+Z$ than for Depend $+\mathrm{EV}$, whereas the family mean square of Affinity $+\mathrm{Z}$ was smaller than that for Depend + EV (Table 1), resulting in a lower heritability point estimate for Affinity $+\mathrm{Z}$. This may be due to differences between the two populations in the frequencies of genes conditioning resistance, which will affect variance among families (33). Depend + EV is a synthetic cultivar developed using 252 parental clones, whereas Affinity $+Z$ is a synthetic cultivar composed of 91 parental clones (7). The greater family mean square values observed for Depend + EV may reflect its having a broader genetic base of parental clones than Affinity $+\mathrm{Z}$.

The primary utility of a heritability estimate in population improvement is that it helps to estimate response based on selection for a metric trait using the following formula: Response $=i h^{2} \sigma_{p}$, where $\mathrm{i}=\mathrm{in}$ tensity of selection, $\mathrm{h}^{2}=$ heritability of the trait, and $\sigma_{p}=$ phenotypic standard deviation of the trait (9). Busch et al. (4) suggested that cultivars require at least $60 \%$ resistant plants to afford maximal field protection against $V$. albo-atrum. Results for 2005 presented in Table 2 suggest that neither Affinity $+\mathrm{Z}$ or Depend + EV have resistance levels this high. The heritability estimates presented here suggest that sufficient additive genetic variance is still available in Affinity $+\mathrm{Z}$ and Depend $+\mathrm{EV}$ for further improving levels of resistance to $V$. albo-atrum. Resistance levels might be more rapidly improved by increasing the intensity of selection by selecting only plants with the most elite phenotypes for use as parents for subsequent generations.

\section{ACKNOWLEDGMENTS}

We thank S. Smith, School of Renewable Natural Resources, University of Arizona, and P. Miklas, United States Department of AgricultureAgricultural Research Service, for critical review of the manuscript.
LITERATURE CITED

1. Alfalfa Council. 2002. Fall dormancy and pest resistance ratings for alfalfa varieties. Alfalfa Council, Kansas City, MO.

2. Atkinson, T. G. 1981. Verticillium wilt of alfalfa: Challenge and opportunity. Can. J. Plant Pathol. 3:266-272.

3. Barnes, D. K., Bingham, E. T., Murphy, R. P., Hunt, O. J., Beard, D. F., Skrdla, W. H., and Teuber, L. R. 1977. Alfalfa germplasm in the United States: Genetic vulnerability, use, improvement and maintenance. U. S. Dep. Agric. Res. Tech. Bull. No. 1571.

4. Busch, L. V., Christie, B. R., Smith, E. A., and Boland, G. 1985. Testing alfalfa cultivars for resistance to an alfalfa strain of Verticillium albo-atrum. Can. J. Plant Pathol. 7:203-205.

5. Christen, A. A. 1982. Demonstration of Verticillium albo-atrum within alfalfa seed. Phytopathology 72:412-414.

6. Christen, A. A., and Peaden, R. N. 1982. Relative importance of sources of Verticillium wilt infestation in alfalfa. (Abstr.) Phytopathology 72:960.

7. Descriptions of Cultivars and Germplasms. 1995. North American Alfalfa Improvement Conference. Online publication.

8. Falconer, D. S. 1981. Heritability. Pages 148 169 in: Introduction to Quantitative Genetics, 2nd. Longman Group Ltd., New York.

9. Falconer, D. S. 1981. Selection: The response and its prediction. Pages 170-187 in: Introduction to Quantitative Genetics, 2nd ed. Longman Group Ltd., New York.

10. Fyfe, J. L. 1964. Hereditary variation in resistance to Verticillium wilt within cultivated Lucerne. J. Agric. Sci. 63:273-276.

11. Gordon, T. R., Correll, J. C., Gilchrist, D. G., and Martensen, A. N. 1989. Verticillium wilt of alfalfa in California. Plant Dis. 73:18-20.

12. Gossen, B. D., and Jefferson, P. G. 2004. A novel source of resistance to Verticillium wilt in alfalfa. Can. J. Plant Sci. 84:401-404.

13. Graham, J. H., Peaden, R. N., and Evans, D. W. 1977. Verticillium wilt of alfalfa found in the United States. Plant Dis. Rep. 61:337-340.

14. Grau, C. R. 1991. Standard Test: Verticillium wilt resistance. North American Alfalfa Improvement Conference. Online publication.

15. Grau, C. R., Delwiche, P. A., Norgren, R. L., O'Connell, T. E., and Maxwell, D. P. 1981. Verticillium wilt of alfalfa in Wisconsin. Plant Dis. 65:843-844.

16. Gray, F. A., and Koch, D. W. 2004. Influence of late season harvesting, fall grazing, and fungicide treatment on Verticillium wilt incidence, plant density, and forage yield of alfalfa. Plant Dis. 88:811-816.

17. Gray, F. A., and Roth, D. A. 1982. Verticillium wilt of alfalfa in Wyoming. Plant Dis. 66:1080.

18. Griffing, B. 1956. Concept of general and specific combining ability in relation to dialle crossing systems. Aust. J. Biol. Sci. 9:463-493.

19. Harper, A. M., and Huang, H. C. 1984. Contamination of insects by the plant pathogen Verticillium albo-atrum in an alfalfa field. Environ. Entomol. 13:117-120.

20. Howard, R. J. 1985. Local and long-distance spread of Verticillium species causing wilt of alfalfa. Can. J. Plant Pathol. 7:199-202.

21. Huang, H. C., Acharya, S. N., Hanna, M. R., Kozub, G. C., and Smith, E. G. 1994. Effect of Verticillium wilt on forage yield of alfalfa in southern Alberta. Plant Dis. 78:1181-1184.

22. Huang, H. C., Hanna, M. R., and Kokko, E. G. 1985. Mechanisms of seed contamination by Verticillium albo-atrum in alfalfa. Phytopathology 75:482-488.

23. Huang, H. C., Harper, A. M., Kokko, E. G., and Howard R. J. 1983. Aphid transmission of Verticillium albo-atrum to alfalfa. Can. J. Plant Pathol. 5:141-147.

24. Huang, H. C., Richards, K. W., and Kokko, E. G. 1986. Role of the leafcutter bee in dissemi- 
nation of Verticillium albo-atrum in alfalfa. Phytopathology 76:75-79.

25. Idaho Agricultural Trade Issues Report. 2004. Idaho State Department of Agriculture, Boise.

26. Issac, I. 1957. Wilt of Lucerne caused by species of Verticillium. Ann. Appl. Biol. 45:550-558.

27. Knapp, S. J., Stroup, W. W., and Ross, W. M. 1985. Exact confidence intervals for heritability on a progeny mean basis. Crop Sci. 25:192-194.

28. Leath, K. T., and Pennypacker, B. W. 1990. Verticillium wilt. Pages 39-41 in: Compendium of Alfalfa Diseases. D. L. Stuteville and D. C. Erwin, eds. American Phytopathological Society Press, St. Paul, MN.

29. Miller, P. R., and Christie B. R. 1991. Genetics of resistance to Verticillium wilt in 'Vertus' alfalfa. Crop Sci. 31:1492-1495.

30. Miller-Garvin, J. E., and Viands, D. R. 1994. Selection for resistance to Fusarium root rot, and associations among resistances to six diseases in alfalfa. Crop Sci. 34:1461-1465.

31. Newcombe, G., and Robb, J. 1988. The function and relative importance of the vascular coating response in highly resistant, moderately resistant and susceptible alfalfa infected by Verticillium albo-atrum. Physiol. Mol. Plant Pathol. 33:47-58.
32. Nguyen, H. T., and Sleper, D. A. 1983. Theory and application of half-sib matings in forage grass breeding. Theor. Appl. Genet. 64:187196.

33. Nyquist, W. E. 1991. Estimation of heritability and predictions of selection response in plant populations. Crit. Rev. Plant Sci. 10:235-322.

34. Page, M. S., Gray, F. A., Legg, D. E., and Kearl, W. G. 1992. Economic impact and management of Verticillium wilt on irrigated alfalfa hay production in Wyoming. Plant Dis. 76:504-508.

35. Panton, C. A. 1967. Observations on the nature of inheritance of resistance of Lucerne to Verticillium albo-atrum. Hereditas 57:333-338.

36. Peaden, R. N., Gilbert, R. G., and Christen, A. A. 1985. Control of Verticillium albo-atrum on alfalfa. Can. J. Plant Pathol. 7:211-214.

37. Pennypacker, B. W., Knievel, D. P., Leath, K. T., Pell, E. J., and Hill, R. R. 1990. Analysis of photosynthesis in resistant and susceptible alfalfa clones infected with Verticillium alboatrum. Phytopathology 80:1300-1306.

38. Pennypacker, B. W., Knievel, D. P., Risius, M. L., and Leath, K. T. 1995. Impact of Verticillium albo-atrum and photosynthetic proton flux density on ribulose-1,5-bisphosphate carboxylase/oxygenase in resistant alfalfa.
Phytopathology 85:132-138.

39. Pennypacker, B. W., and Leath, K. T. 1993 Anatomical response of resistant alfalfa infected with Verticillium albo-atrum. Phytopathology 83:80-85.

40. Pennypacker, B. W., Leath, K. T., and Hill, R. R. 1991. Impact of drought on the expression of resistance to Verticillium albo-atrum in alfalfa. Phytopathology 81:1014-1024.

41. Ray, I. M., Townsend, M. S., Muncy, C. M., and Henning, J. A. 1999. Heritabilities of water use efficiency traits and correlations with agronomic traits in water stressed alfalfa. Crop. Sci. 39:494-498.

42. Smith, E. G., Acharya, S. N., and Huang, H. C. 1995. Economics of growing Verticillium wilt resistant and adapted alfalfa cultivars in Western Canada. Agron. J. 87:1206-1210.

43. Tuite, J. 1969. Plant Pathological Methods. Burgess Publishing Co. Minneapolis, MN

44. Viands, D. R. 1985. Comparison of 'Maris Kabul' with 'Vertus' alfalfa for resistance to Verticillium wilt. Crop Sci. 25:1096-1100.

45. Viands, D. R., Lowe, C. C., Bergstrom, G. C., Vaughn, D. L., and Hansen, J. L. 1992. Association of level of resistance to Verticillium wilt with alfalfa forage yield and stand. J. Prod. Agric. 5:504-509. 